\title{
HOW TO PLAN INTERACTION OF TRANSPORT NETWORK AND RESIDENTIAL SPACE IN AN URBAN ENVIRONMENT: CASE OF BATNA CITY
}

\author{
Haddad Louiza', Aouachria Zeroual ${ }^{2}$ \\ ${ }^{1}$ Laboratory of natural hazards and territorial planning, University Batna2, Algeria \\ ${ }^{2}$ Applied Energy Physics Laboratory (LPEA), University Batna1, Algeria
}

Received 22 May 2021; accepted 25 August 2021

\begin{abstract}
The main purpose of this work is to show how to optimize the use of urban soils in conjunction with its transportation network to save residential areas from the air pollution generated by vehicles. The model evokes the spatial elements and problems necessary for the representation of the urban environment with precision in the development of residential land use. This model also predicts the degree of pollution of already existing residential areas. The approach is based on the minimum distance between the road and the residential area for which the air quality remains acceptable for human health. The mathematical analysis will allow a better planning of the urban transport network. The effect and impact of the transport network on urban air quality is presented based on geo-spatial analyzes. The results will help to reduce the negative impacts of transport on the air quality, particularly in the urban domain. Through this mathematical modelling, sustainable development will be achieved by defining the residential zone that will be spared from pollution due to the transport network and delimit the polluted part of the already existing zone. The solution adopted is to show how the soil must be exploited with regards to the transport network and residential areas.
\end{abstract}

Keywords: transportation, mathematical modelling, air pollution, urban, land use, environment.

\section{Introduction}

Increasing urbanization leads to a growing need for commerce and mobility to improve accessibility to different areas. Those will make heavy traffic. Thus, the latter will be mainly concentrated in urban areas where its impact will appear dramatically. In fact, air pollution in urban areas is mainly caused by transport systems, less importantly, by industrial activities (Haddad et al., 2015). The development of a sustainable economy attracts more and more attention worldwide. As a result, many countries have taken specific initiatives to decarbonize their transport sector in particular (Wang et al., 2012; Vithayas et al., 2011; Boulanger et al., 2014; Boulanger, 2014). Air quality, as one of the characteristics of the transport system, is considered a major criterion for the protection of public human health. Therefore, the air pollution emitted by transport systems can be linked to the occupation of urban soils and proportionally to the urban transport network (Hadipour et al. 2009). The growing demand for the rest of total residential areas and the development of cities has led to environmental problems

${ }^{2}$ Corresponding author: zeroual.aouachria@univ-batna.dz 
(Bell et al., 2000; Ranjan, 2001; Haripur et al., 2009). Effects of air pollution on health are alarming. Indeed, local and urban pollution at light concentrations is manifested in the lungs, heart and eyes and affects large populations. Transport is one of the most polluting sources of $\mathrm{CO}$, especially in urban areas (Host, 2013), with subsequent adverse human health effects (Comrie et al., 1999; Faiz and Sturm, 2000; Colvile et al., 2001; Chan et al., 2002; Kohler et al., 2005). In any case, despite these limits, the results of numerous studies indicate an increased risk of occurrence or exacerbation of cardiorespiratory pathologies or death for populations living near significant sources of road traffic (Host, 2013). Other studies also link this to cancer (Gauderman et al., 2005). Distance seems to play a fundamental role. In Sweden, it was highlighted an increased risk of asthma $(+40 \%)$ and obstructive pulmonary disease $(+64 \%)$ in people living within 100 meters of a road where traffic exceeds 10 vehicles / minute (Lindgren et al., 2009). In Germany, it is showed an $85 \%$ increased risk for heart disease in people living within $150 \mathrm{~m}$ of a major highway (Gzar et al., 2009).

Air pollutants are so named because they are regulated, by the EPA, by developing criteria based on human health and the environment in order to set allowable levels. As a result, the Clean Air Act requires the EPA to hold current national ambient air quality standards for those pollutants that are commonly found in outdoor air and can harm human health or the environment. When the fuels are not completely burnt, there is a release of carbon. Transport systems are the source of the majority of $\mathrm{CO}$ emissions (Department of Transport, 1996, Turner, 1995). These sources include both on-road and off-road vehicles and stationary internal combustion engines (Yin et al., 2006). So, the urban space, with strong congestion, is the seat of high concentrations of $\mathrm{CO}$, because in these cities, up to $95 \%$ of these $\mathrm{CO}$ emissions come from automobile exhaust gases. The strategy of the EPA, in the fight against pollution, lies in the close monitoring of the emission process; the identification of risks is used as a regulatory decision factor. The focus on emission sources has led to analyses of the types of pollutants present in effluents, air emissions and waste dumps, and the detection of chemical, biological and sometimes radiological agents. In the 1970s, the link between certain chemicals and certain diseases, such as cancer, was established by a series of biological tests or, in the case of chemicals such as vinyl chloride and asbestos, by epidemiological studies. The problem in this research is assumed as studied pollution emission and dispersion from several vehicles by using Gaussian model (Clean Water Action Council, 2008; Haughton et al., 2003; Lacoste et al., 2002; Żeliński et al., 2017).

To address these problems, the investigation of methods of reducing emissions from vehicle exhausts becomes essential, but not by reducing the volume of traffic that will undoubtedly affect the mobility of the population and the economy. Reducing pollution in urban areas requires a reexamination of planning and uses policies. It is necessary to make real changes in urban transport and in the behaviour of its users. The solution to reduce the impact of these emissions is to choose how the land is exploited relative to the transport network and residential areas. Beyond questions of displacement, it is more broadly the question of the proximity health link that is raised: the challenge is to rethink land use planning, to limit distances by recreating 
proximities (Meszaros et al., 2005). The sectorial distribution of funding and the lack of political autonomy and resources represent the challenges to be taken into account by institutions and local authorities. All these promote competition for resources between authorities leading to antagonism rather than synergy. When coordination between the different actors of spatial planning, housing, public transport and the environment is absent, these challenges become unmanageable (Fenton et al., 2017; OECD, 2013: Haughton et al., 2003; Jafarmadar and Nezhad, 2015).

To circumvent these antagonistic effects of the transport system, land use must be optimized by taking into account the relationships of the transmission system and the location of residential areas in order to avoid the effects of pollution on human health. Approach adopted to solve this problem; we present a mathematical geo spatial model of the studied site combining land use, road type and air quality. This approach allows us to delimit the residential zones and those of urban road network and the former zones already existing for possible corrections which they require.

\section{Materials and Method}

\subsection{Materials}

Wilaya de Batna is located in the north-east of the Algerian territory fig.1. It is bounded on the north by the wilaya of Mila, Oum El-Bouaghi, on the east by the wilaya of Setif Khenchela, on the west by the wilaya of M'Sila and on the south by the wilaya of Biskra. The climate is semi-arid. its winter is cold with temperatures can reach -2 to $+5{ }^{\circ} \mathrm{C}$ and the summer is very hot with temperatures that can reach $45^{\circ} \mathrm{C}$. Although the rainfall is mediocre $300 \mathrm{~mm}$, agriculture plays an important role in the activity of the population.

The economy of the wilaya is mainly focused on agriculture. The industry is in full development, partly because of the presence of important mineral resources. It also benefits from important tourist sites, including the Timgad site, Roufi balconies, geothermal springs and many other historic sites. All these parameters amplified the volume of traffic in different parts of the city which will pose the health problem which justifies the choice of this subject.
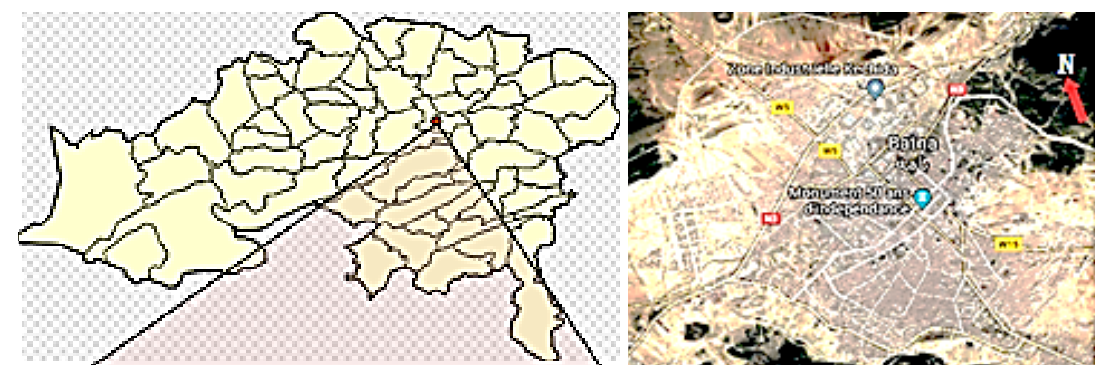

Fig. 1.

Geographic Location of the Study Area 


\subsection{Method}

A series of mathematical correlations combined with given models to calibrate a new model in relation to a given problem constitutes what is called a mathematical trajectory. Carbon monoxide has the advantage of being present at both;

- At higher concentrations than other commonly controlled gases $\left(\mathrm{H}_{2} \mathrm{~S}, \mathrm{~N}_{\mathrm{ox}}\right)$;

- Have a rather long chemical response time compared to other pollutants. This makes its detection simpler and more reliable (Dorling et al., 2000; Petro et al., 2017; Jaworski et al., 2017; Hatam et al., 2009).

In unstable and neutral conditions, a continuously emitted plume will appear under different structures. the ascending heat flow and the descending movement, during transport, cause vortices in the case of this due to unstable conditions while in the so-called neutral conditions, this instability is purely mechanical (see Fig. 2a.) and the plume resulting looks like a cone.

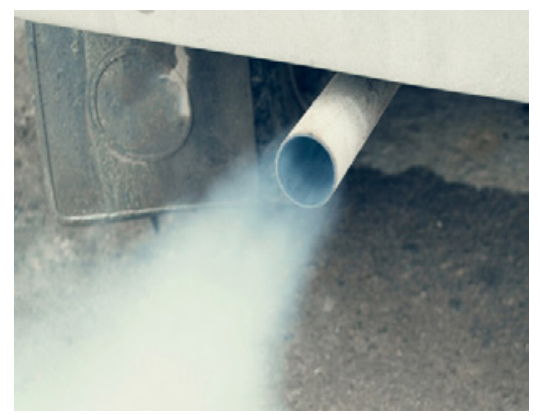

a)

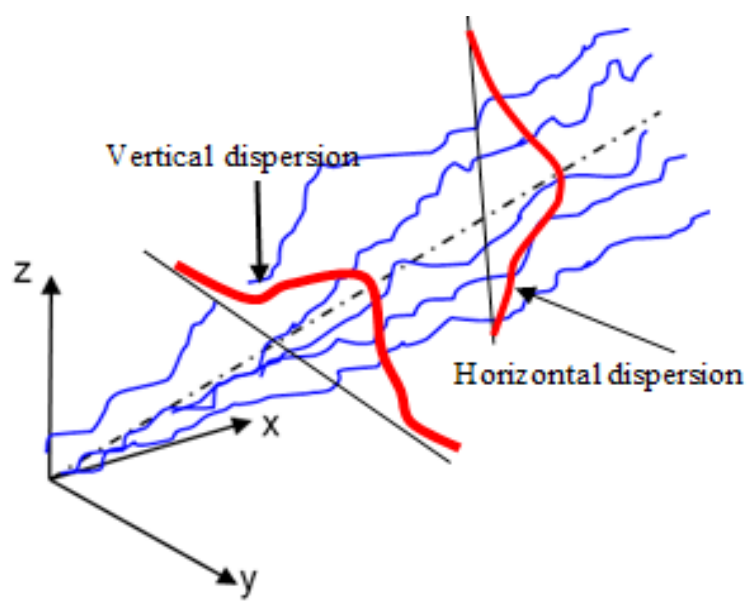

b)

Fig. 2.

a) A vehicle Exhaust Fumes causing Air Pollution Profile (personal photo); b) Plume Rise and its Dispersion in $2 D$ 
The mean of the approach used is based on the maximum concentration at ground level of carbon monoxide (CO). This maximum, rate resulting from the $\mathrm{CO}$ mass fraction generated from the exhausts of the vehicles, is the product of the horizontal and vertical propagation of the pollutant plume in the mean direction of wind blowing Fig. 2. The evolution of $\mathrm{CO}$ concentration will then be described by a restrictive function of the field of study in improvement and sustainable development (Fenton et al., 2017; OECD, 2013). In unstable and neutral conditions, a continuously emitted plume will appear under different structures. the ascending heat flow and the descending movement, during transport, cause vortices in the case of this due to unstable conditions while in the so-called neutral conditions, this instability is purely mechanical (see Fig. 2b) and the plume resulting looks like a cone.

Following the above analysis, the minimum safety distance $\left(\mathrm{D}_{\text {min }}\right)$ between roads and the residential area to avoid air pollution emitted by vehicles is the distance at which the total $\mathrm{CO}$ emission rate from vehicles is reduced at $10 \mathrm{mg} / \mathrm{m}^{3}$. This optimal distance between the residential area and the urban transport network is defined according to the good air quality, which is the element on which the construction of our model is based. A series of mathematical correlations combined with given models to calibrate a new model in relation to a given problem constitutes what is called a mathematical trajectory. The main state of this method is shown schematically in Fig.3.

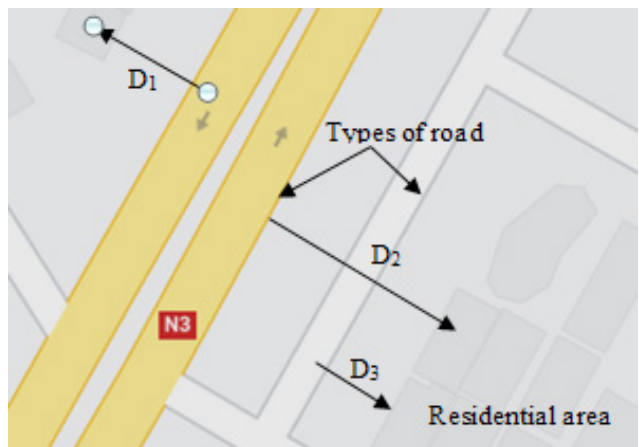

Fig. 3.

Schematic of the Main State showing the Standard Value of the Pollutant CO in $8 \mathrm{~h}$

The process of dispersion and diffusion of the $\mathrm{CO}$ pollutant can be analyzed by the use of the Gaussian equation. The Gaussian model allows for short or long-term simulations of the pollutant diffusion surface or emitter point. The model calculates a plume of pollutant from the emission source, reflecting on the ground, according to an atmospheric stability class and a given wind according to the following equation for a short-term calculation (Dorling et al., 2000; Petro et al., 2017).

$Y_{C O}^{\text {tot }}=\frac{W}{2 \pi U \sigma_{z} \sigma_{y}} \cdot \exp \left(-\frac{y^{2}}{2 \sigma_{y}^{2}}\right)\left[\exp \left(-\frac{\left(z-z_{0}\right)^{2}}{2 \sigma_{z}^{2}}\right)+\exp \left(-\frac{\left(z \mp z_{0}\right)^{2}}{2 \sigma_{z}^{2}}\right)\right]$

$Y_{C O}^{\text {tot }}$ : is the concentration of pollutants in $\mathrm{g}$ $/ \mathrm{m}^{3}$, $\mathrm{Q}$ is the source pollutant rate flow in $\mathrm{g} / \mathrm{s}, \mathrm{u}$ is the average wind speed in $\mathrm{m} / \mathrm{s}, \sigma_{\mathrm{y}}$ is the standard deviation of the horizontal turbulence distribution and $\sigma_{z}$ is the 
standard deviation of the vertical turbulence distribution; $h$ is the effective height of the pollutant source. By applying the security standard of air quality near the ground, equation (1) becomes:

$Y_{C O}^{t o t}=\frac{W}{\pi U \sigma_{z} \sigma_{y}} \cdot \exp -\frac{1}{2}\left(\frac{y^{2}}{\sigma_{y}^{2}}\right)\left[\exp -\frac{1}{2}\left(\frac{z_{0}{ }^{2}}{2 \sigma_{z}^{2}}\right)\right]$

The exponent $\mathrm{p}$ varies and is approximately 0.07 for unstable conditions and 0.55 for stable conditions (Turner, 1994) (see Table 1). In order to define the safety distance $\left(D_{\text {min }}\right)$, it is necessary to apply the total CO emission rate of the vehicles, the rising distance of the emitted $\mathrm{CO}$, the average wind speed and the standard deviation of the vertical and horizontal wind direction. The calculation of the total emission rate of $\mathrm{CO}$ of the vehicles, counts the capacity of the route in replacement of the volume of traffic and the possible capacity of the road, developed by (Jaworski et al., 2017) is:

$W=V_{\text {road }} \cdot q_{c o}$ with $V_{\text {road }}=\frac{s_{p v}}{c_{m} w_{t}}$

and $S_{p v}=l \cdot L_{p}$

Where $Q$ is the total $C O$ emission rate of the vehicles, VR is the possible road capacity at the CO stability time, $q_{c o}=$ average possible $\mathrm{CO}$ emission rate for a vehicle, $\mathrm{S}_{\mathrm{pv}}=(1 . \mathrm{Lp})$ is the road surface crossed per vehicle, $\mathrm{C}_{\mathrm{m}}=$ Average vehicle use of space-time $\left(\mathrm{m}^{2}\right)$ and $\mathrm{Vt}$ is the average vehicle speed based on the type of road $(\mathrm{m} / \mathrm{s})$. Thus, the concentration of the pollutant reaches its peak within five minutes of the exhaust gas vehicles. Then the maximum reasonable time for calculating the number of passing vehicles is considered less than 15 min (Bell et al., 2000; Hatam et al., 2009).

$\mathrm{Cm}$ is a function of the percentage of vehicle types and their actual size. $W$ and $V_{t}$ have been applied depending on the road types (Table 1). $L_{p}$ is the time spent per vehicle which refers to the size of the greed chosen for the study of air pollution; $q c$ was obtained through a purely mathematical process, taking into account elements characteristic of the phenomenon of the pollutant diffusion. The climb height $\mathrm{h}$ of the CO, emitted by vehicle exhaust, is determined by (Turner, 1994):

$h=\alpha F_{0} t^{1 / 3} / u^{1 / 3}$ with $F_{0}=g v r_{s}^{2}\left(\left|-T_{a} / T_{s}\right|\right)_{R}$

Where $h$ is the height of the rise of the $\mathrm{CO}, \mathrm{F}_{0}$ is the buoyancy factor $\left(\mathrm{m}^{4} / \mathrm{s}^{3}\right)$, $\mathrm{t}$ is the time in (s), $\mathrm{u}$ the horizontal speed component of the ambient air, vs is the gas output speed, $\mathrm{g}$ is the acceleration gravitation $\left(\mathrm{m} / \mathrm{s}^{2}\right)$. The dispersion of pollutants from vehicle exhaust is strongly influenced by solar radiation and the average wind speed in the study area. Based on the historical data and the parameters in Table 1, the meteorological conditions in the study area coincide with the situation assigned by the B curve in Fig. 4. The spread of $\mathrm{CO}$ occurs in the directions $\mathrm{y}$ and $\mathrm{z}$.

\section{Table 1}

Key to Weather Stability Classes

\begin{tabular}{|c|c|c|c|c|c|}
\hline $\begin{array}{c}\text { Wind Speed } \\
(\mathbf{m} / \mathbf{s})\end{array}$ & $\begin{array}{c}\text { Day Incoming Solar } \\
\text { Radiation Fort Moderate } \\
\text { Light Weight }\end{array}$ & Night & Finely & Covered \\
\hline$<2$ & A & A-B & B & E & F \\
\hline $2-3$ & A- B & B & C & E & F \\
\hline $3-5$ & B & B- C & C & D & E \\
\hline $5-6$ & C & C- D & D & D & D \\
\hline$>6$ & C & D & D & D & D \\
\hline
\end{tabular}



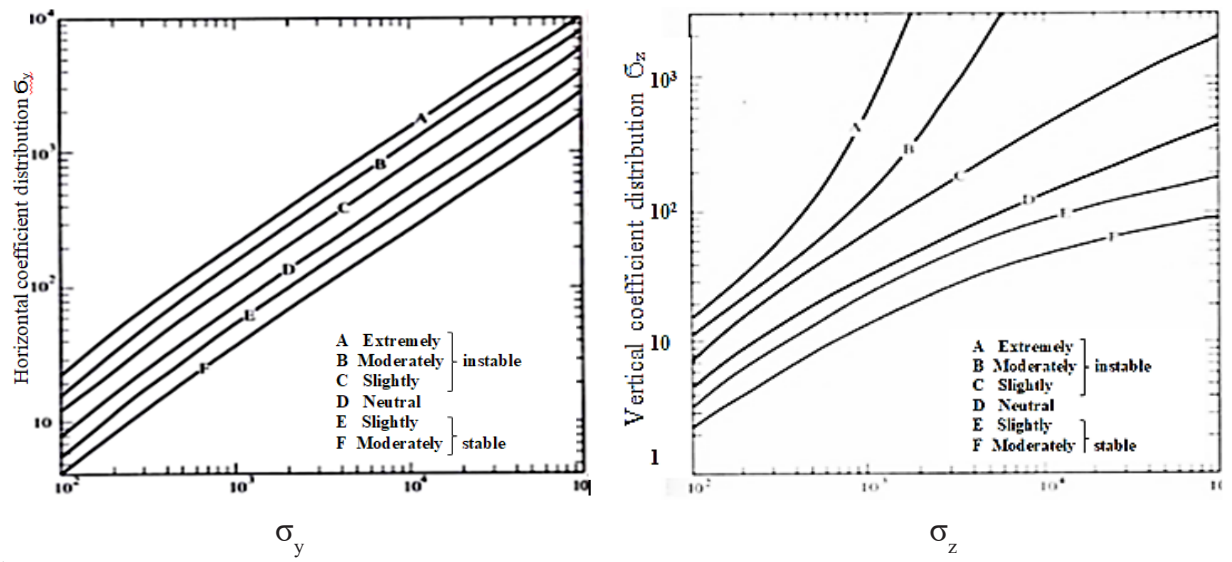

Fig. 4.

Components of Dispersion Coefficients $\sigma_{y} \sigma_{z}$

We assume that the concentration of $\mathrm{CO}$ equal to the standard value for 8 hours without risk: $\mathrm{C}_{\mathrm{x}}=0.01 \mathrm{~g} / \mathrm{m}^{3}$ i.e. the safety distance $\mathrm{D}_{\min }$, equation (1) becomes:

$\sigma_{y} \sigma_{z}^{3}=\frac{16.32 Q h^{2}}{u}$

But this desired distance does not appear explicitly in this equation although it is linked to the spread of pollutants in space. We suggest that the standard deviations are based on the distance and we create this relationship as follows:

$\left(\sigma_{y} \sigma_{z}\right)^{3}=f\left(D_{\min }\right)$

$\sigma_{\mathrm{y}}$ and $\sigma_{\mathrm{z}}$ will be expressed as a $f\left(\mathrm{D}_{\text {min }}\right)$ for the standard value of the pollutant $\mathrm{CO}$ in $8 \mathrm{~h}$, $\left(0.01 \mathrm{~g} / \mathrm{m}^{3}\right)$; using parameters in table 1 and after some simplifications, the equation (1) can be transformed in form:

$f\left(D_{\min }\right)=\frac{19.32 W z_{0}^{2}}{u}$

Where the function, $f\left(D_{\min }\right)$, replaces the product: $\left(\sigma_{\mathrm{y}} \sigma_{\mathrm{z}}\right)^{3}$. Note that the safety distance

$\mathrm{D}_{\min }$ is not explicit in this equation. Based on the graph of Fig. 4, and the approximation applying to Crow 1 and Louver's formula we give $\sigma_{\mathrm{y}}=0.32 \mathrm{D}_{\min }$ and $\sigma_{\mathrm{z}}=0.24 \mathrm{D}_{\text {min }}$. Based on eq. 6 , we obtain:

$f\left(D_{\min }\right)=4.433 .10^{-3}\left(D_{\min }^{4}\right)$

From eq. (6) and (7) we can obtain:

$4.433 \cdot 10^{-3}\left(D_{\min }^{4}\right)=\frac{19.32 W z_{0}^{2}}{u}$

$\left(D_{\text {min }}\right)=8.142 \frac{w^{\frac{1}{4}} z_{0}^{\frac{1}{2}}}{u^{\frac{1}{4}}}$

We can then generate the model as:

$D_{\min }=k \frac{W^{\frac{1}{4}} z_{0}^{\frac{1}{2}}}{u^{\frac{1}{4}}}$

\subsection{Model Sensibility and Calibration}

As any model represents a function of variables whose influences on its behaviour are more or less sensitive to each other, it is necessary to establish an analysis of 
the sensitivity of the main variables of the problem on the model. To do so, a comparison of the effects of $h, q$ and $U$ on the calculations of the minimum acceptable distance to human health was performed to examine the error of each parameter in order to test the precision and validation of the model. The coefficient $k$ of the eq. 7 depends on site conditions and meteorological parameters; it must be calibrated for the study site using the measured data of this site taking into account the study conditions and the measurement data as noticed in Table 2.

\section{Table 2}

Simulated Properties Samples by DSM Batna Data

\begin{tabular}{|c|c|c|c|c|c|c|}
\hline $\begin{array}{c}\mathbf{u} \\
\mathbf{m} / \mathbf{s}\end{array}$ & $\begin{array}{l}\mathbf{H} \\
\mathbf{m}\end{array}$ & $\mathbf{Q}$ & $d_{\min }$ calculated & $\begin{array}{c}h^{1 / 2} Q^{1 / 4} \\
U^{-1 / 4}\end{array}$ & $\left(D_{\text {min)field }}\right.$ & $\mathbf{K}_{\text {Justifié }}$ \\
\hline 8.50 & 0.12 & 1665 & 10.07 & 1.38 & 9.83 & 7.12 \\
\hline 8.85 & 0.12 & 1665 & 10.11 & 1.39 & 8.72 & 6.27 \\
\hline 9.18 & 0.12 & 1665 & 9.98 & 1.37 & 12.62 & 9.21 \\
\hline
\end{tabular}

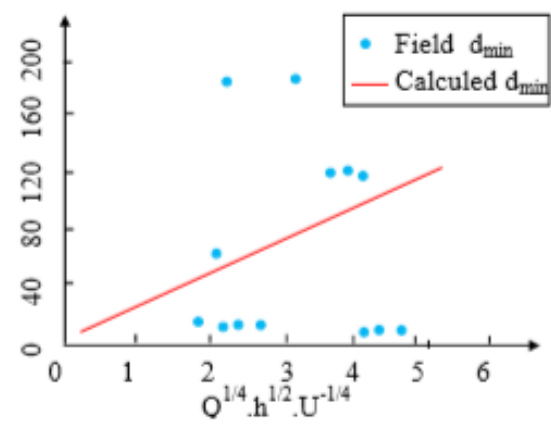

Fig. 5.

Comparison of Field and Calculated ${ }_{\text {Dmin }}$

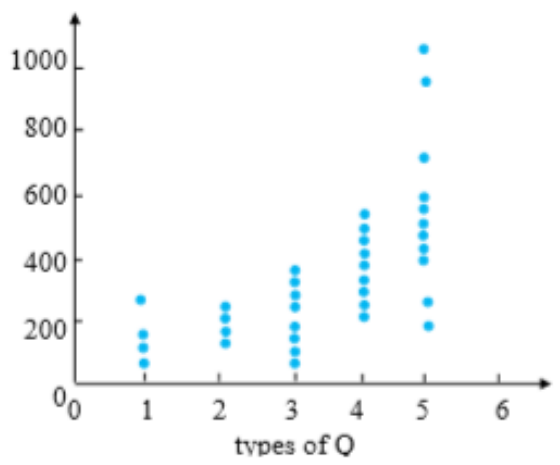

Fig. 6 .

Relation between $Q$ Field $D_{\min }$ 


\subsection{Validation}

The comparison of the model predictions with the field data recorded by the different measuring stations shows a valid agreement. The sensitivity analysis and calibration of the model is performed by applying the values of the calculated ${ }_{D \text { min }}$ parameters (after calibration) and ${ }_{D \min }$ resulting from the measured data and analysing the mathematical relationship of these two parameters which shows us an acceptable level of accuracy. This mathematical relationship shows an acceptable level of accuracy, $21.06 \%$. Fig.7. Applied to the generalized values of the transport system components and weather conditions, the model should be adapted to the study area.

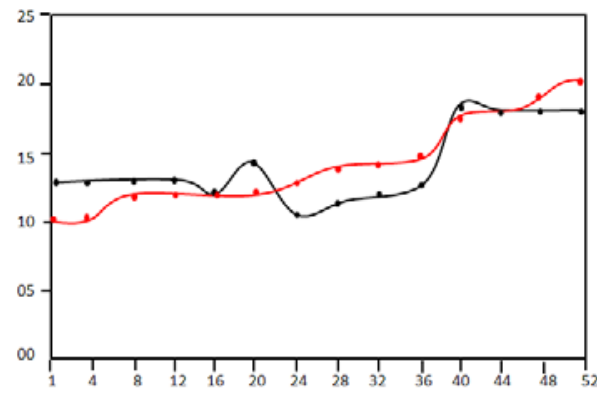

Fig. 7.

Error between Fields's $D_{\min }$ Real and Calculated

\section{Results and Discussion}

The constants used are assigned in Table 3. the exhaust gas temperature $\left(\mathrm{T}_{\mathrm{s}}\right)=395 \mathrm{~K}$ average exit $\mathrm{CO}$ velocity $\left(\mathrm{V}_{\mathrm{s}}\right) 0.4 \mathrm{~m} / \mathrm{s}$, mean annual atmospheric pressure for Batna (P) 1000, Batna $301 \mathrm{~K}$, normal use of the average space-time

Table 3

$D_{\min }$ Calculated for Different Road Types

\begin{tabular}{|c|c|}
\hline Type of Route & $\mathbf{D}_{\text {min }}$ \\
\hline Local & 18.32 \\
\hline Artery & 15.43 \\
\hline Highway & 12.77 \\
\hline
\end{tabular}

Potentially polluted areas have been subdivided into three areas: areas polluted by collector roads, local roads, and highways. From the $\mathrm{D}_{\min }$ values in Table 3, three areas polluted by different of a vehicle $(\mathrm{Cm}) 7.3 \mathrm{~m}^{2} / \mathrm{s}$. The application of generalized values determines the minimum distances between roads and residential settlements which permit the concentration of Co tolerable for human life, $\mathrm{D}_{\text {min }}$, depending on the types of roads that crisscross the city of Batna and the results are presented in Table 3. types of roads are plotted. Areas with good air quality are highlighted by analysing the effects of the three types of road and deselecting areas that are effectively polluted by type of road. 
For example, Figure 8 illustrates the polluted areas of roads. Finally, the map of the Batna's potential pollution zones were originated by superimposing the three results of mas of potentially polluted areas by type of route. The Fig. 8 shows much more of $30.2 \%$ is potentially polluted by transport and it is useful for delineating unpolluted areas.

Figure 11 shows a map resulting from the combination of the map of residential areas with the map of potential pollution areas for analysis of current residential uses concerning local road case. Essentially, we can observe on the map of Figure 11, about $19.37 \%$ of recent residential localities are already polluted areas from vehicle emission. The model provides the possibility to modify the governing parameters of the process of dynamic propagation of pollutants in the atmosphere. It is characterized by decisionmaking capabilities.

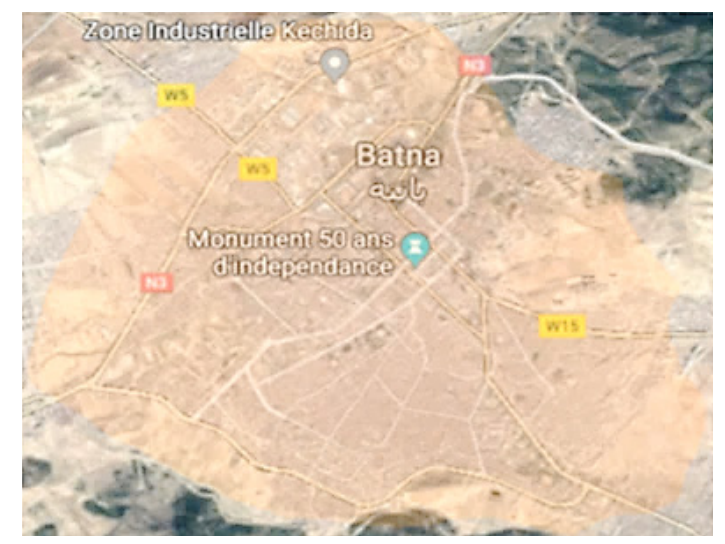

Fig. 8.

Pollution Corresponding to Local Road

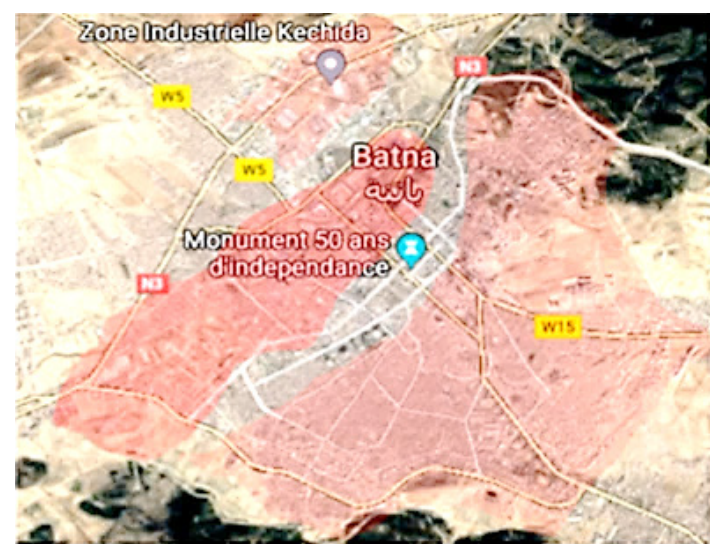

Fig. 9.

Pollution Corresponding to Arteries Road 


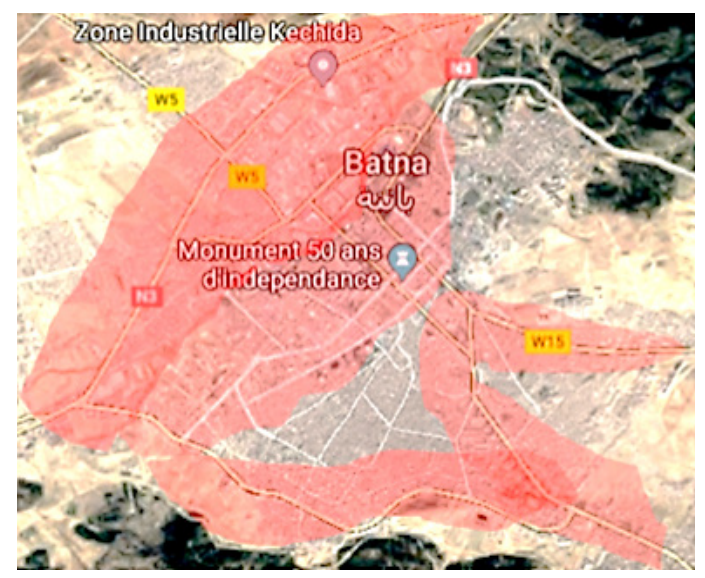

Fig. 10.

Pollution Corresponding to Auto Road

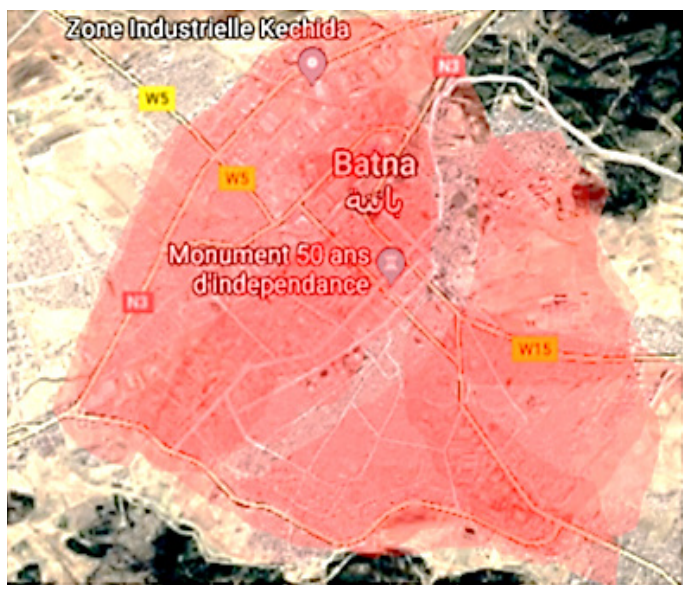

Fig. 11.

Corresponding Map of the Superposition of Different Types of Pollution

\section{Conclusions}

A new scientific approach has been developed which identifies how to successfully represent the relationship between land and urban networks exploitation, on the one hand and on the other, guides us to model air pollution due to transport system and analyse land use and urban networks. This approach is able to support planners with a range of options. Modelling this problem is a challenge represented by antagonistic effects. Indeed, some areas may be more suitable than others for the development of residential and urban transport networks and the criteria are taken into account. This adequacy depends largely on the importance of the element, "air quality", which cannot be ignored in all transport projects. 
The model was not sensitive to small changes in input parameter values. Therefore, in specific weather conditions, areas away from emission sources (roads) can also be heavily polluted. Indicators are based on data to achieve the objective of the model.

It is expected that planners studying the spatial distribution of the transport system and land use will use the model incorporating project-specific parameters to benefit from its assistance with a clear awareness of its limitations. It should be noted that the effectiveness of the model will depend on the quality of the data used.

It is substantial to note that this model accompanies planners in proposing alternative sites in urban development plans and in designing a link between transport and the health issue. This is tantamount to thinking about transport in terms of sustainable development, that is to say a development that is healthy and beneficial for all.

\section{References}

Bell, M. C.; Blake, M. 2000. Forecasting the Pattern of Urban Growth with PUP: a Web-based Model Interfaced with GIS and 3D Animation, Journal of Environment and Urban Systems 24(6): 559-581.

Boulanger, A.G.; Chu A.C.; Max S.; Waltz D., 2014. Vehicle electrification: status and issues. In Proceedings of the IEEE, 99(6):1116-1138.

Boulanger, G.M. 2014. Reducing carbon emissions by introducing electric vehicle enhanced dedicated bus lanes. In Proceedings of the 2014 IEEE intelligent vehicles symposium, Dearborn, 1011-1016.
Chan, L.Y.; Lau, W.L.; Zou, S.C.; Cao, Z.X.; Lai, S.C. 2002. Exposure level of carbon monoxide and respirable suspended particulate in public transportation modes while commuting in urban area of Guangzhou, China, Atmospheric Environment 36(38): 5831-5840. doi: 10.1016/S1352-2310(02)00687-8.

Colvile, R.N.; Hutchinson, E.J.; Mindell, J.S.; Warren, R.F. 2001. The transport sector as a source of air pollution, Atmospheric Environment 35(9): 1537-1565. https://doi.org/10.1016/S1352-2310(00)00551-3.

Comrie, A.C.; Diem, J.E. 1999. Climatology and forecast modelling of ambient carbon monoxide in Phoenix Arizona, Atmospheric Environment 33(30): 5023-5036. doi: 10.1016/S1352-2310(99) 00314-3.

Department of Transport. 1996. Transport Statistics Great Britain. UK.

Dorling, D.; Pritchard J. 2010. The Geography of Poverty, Inequality and Wealth in the UK and Abroad: Because enough is Never Enough, Applied Spatial Analysis and Policy 3(2): 81-106. doi: 10.1007/s12061-009-9042-8.

Faiz, A.; Sturm, P.J. 2000. New directions: Air pollution and road traffic in developing countries, Atmospheric Environment 34(27): 4745-4746. doi:10.1016/S1352$2310(00)$.

Fenton, P.; Gustafsson S. 2017. Moving from highlevel words to local action-governance for urban sustainability in municipalities, Current Opinion in Environmental Sustainability 26: 129-133. doi: 10.1016/j. cosust.2017.07.009.

Gauderman, W.J.; Avol, E.; Lurmann, F.; Kuenzli, N.; Gilliland, F.; Peters, J.; McConnell, R. 2005. Childhood asthma and exposure to traffic and nitrogen dioxide, Epidemiology 16: 737-743. 
Gzar, H. A. Kseer, K. M. 2009. Pollutants emission and dispersion from flares: A gaussian case-study in Iraq, Al-Nahrain Journal of Science 12(4): 38-57.

Haddad, L.; Aouachria, Z.; Haddad, D. 2015. Impact of the transport on the urban heat island, International journal for traffic and transport engineering 5(3): 252 - 263. doi: 10.7708/ijtte.2015.5(3).03.

Hadipour, M.; Pourebrahim, S.; Mahmmu, A.R. 2009. Mathematical modelling considering air pollution of transportation: an urban environmental planning, case study in Petaling Jaya, Malaysia, Theoretical and Empirical Researches in Urban Management 4(13): 75-92.

Haughton, G.; Hunter, C. 2003. Sustainable Cities. Rutledge publisher, 1st edition, UK. 368p.

Hoffmann, B.; Moebus, S.; Stang, A.; Beck, E.M.; Dragano, N.; Mohlenkamp, S.; et al. 2006. Residence close to high traffic and prevalence of coronary heart disease, European Heart Journal 27(22): 2696-2702.

Host, S. 2013. Exposition à la pollution atmosphérique liée au trafic routier et risques sanitaires [In English: Exposure to air pollution linked to road traffic and health risks], VertigO - la revue électronique en sciences de l'environnement [consulté le 21 juin 2013. http://vertigo. revues.org/12816].

Jafarmadar, S.; Nezhad, A. S. 2015. Pollutant's emission and dispersion from elevated, gas flare: c.s. of Aghajary, J. of Industrial Pollution Control 31(2) 323-331.

Jaworski, A.; Lejda, K.; Madziel, M. 2017. Emission of Pollution from Motor Vehicles with Respect to Selected Solutions of Round about Intersections, Combustion Engines 168: 140-144.
Kohler, M.U.; Corsmeier, U.; Vogt, U.; Vogel, B. 2005. Estimation of gaseous real world traffic emissions downstream a motorway, Atmospheric Environment 39(31): 5665-5684. doi:10.1016/j.atmosenv.2004.09.088.

Lacoste, O.; Spinosi, L. 2002, Distance, proximité, accessibilité, attraction et recours de la population vis-à vis $d u$ système de soins [In English: Distance, proximity, accessibility, attraction and appeal of the population to the healthcare system]. ORS Nord - Pas-de-Calais, 73 p.

Lindgren, A.; Stroh, P.; Montnemery, U.; Nihlen, K.; Jakobsson, A.; Axmon, A. 2009. Traffic-related air pollution associated with prevalence of asthma and copd/chronic bronchitis. A cross-sectional study in southern Sweden, International journal of health geographics, 8(1): 1-15. doi: 10.1186/1476-072X-8-2.

Meszaros, T.; Haszpra, L.; Gelencser, A. 2005. Tracking Changes in Carbon Monoxide, Budget over Europe between 1995 and 2000, Atmospheric Environment 39(38): 7297-7306.

OECD. 2013. Urban Policy Reviews, Chile. OECD Publishing. Available from Internet: <https://doi. org $/ 10.1787 / 23069341>$.

Petro, F.; Konecky, V. 2017. Calculation of Emission from Transport Services and Their Use for Internalisation of External Cost in Road Transport, Procedia Engineering 192: 677 - 682 .

Ranjan, K. 2001. Development of Spatial and Attribute Database for Planning and Managing Rural Service Centres in Kendrapara District, Orissa, India: A GIS Based Information, Journal of Applied Gerontology 3(1): 99-105. 
Turner, D. B. 1995. Atmospheric Dispersion Estimates, an Introduction to Dispersion Modelling. Lewis USA publisher, $86 \mathrm{p}$.

Turner, D. B. 1994. Workbook of atmospheric dispersion estimates: an introduction to dispersion modelling. 2nd Ed., CRC Press, London, 192p.

Vithayas, R.P.; MacGill, I.F. 2011. Generation portfolio analysis for low-carbon future electricity industries with high wind power penetrations. In Proceedings of the 2011 IEEE Trondheim PowerTech, 1- 6.

Wang, S.; Djilali, D. 2012. Toward low carbon energy systems: the convergence of wind power, demand response, and the electricity grid. In Proceedings of the
2012 IEEE international conference on innovative smart grid technologies-Asia (ISGT Asia'12), 1-8.

Yin, Y.; Lawphongpanich, S. 2006. Internalizing emission externality on road networks, Transportation Research Part D: Transport and Environment 11(4): 292-301.

Żeliński, J.; Kaleta, D.; Telenga-Kopyczyńska, J. 2017. Empirical estimation of virtual point source height over a bank of coke ovens, Environmental Modeling \& Assessment 22(1): 17-26.

\section{jitte 34}

